\title{
O trabalho do professor de Física no ensino médio: um retrato da realidade, da vontade e da necessidade nos âmbitos socioeconômico e metodológico
}

\author{
The Physics teacher's work in high school: \\ a picture of reality, the will and the need in socioeconomic \\ and methodological areas
}

Renato Marcon Pugliese ${ }^{1}$

\begin{abstract}
Resumo: Partimos da hipótese de que a aprendizagem de física no ensino médio no Brasil está muito aquém da ciência e da tecnologia atuais e de que os professores estão insatisfeitos com sua prática cotidiana, para defendermos a tese de que é preciso romper com a atual estrutura de trabalho do professor se for almejada uma formação científica cidadã, autônoma, crítica e democrática. Estudamos o trabalho docente na lógica do capitalismo contemporâneo e como a física e a pesquisa em ensino de física (PEF) vêm sendo construídas. Aplicamos um questionário a professores de física de nível médio de escolas públicas da cidade de São Paulo e concluímos que a realidade do trabalho lhes impede que preparem melhor suas aulas e que tornem a física viva, como eles têm vontade; mantêm aulas expositivas, ensinando a física clássica de modo tradicional, demonstrando necessidade de mudanças urgentes.

Palavras chave: Trabalho docente. Ensino de Física. Ensino médio. Formação de professores. Escola pública.
\end{abstract}

\begin{abstract}
We start from the hypothesis that physics learning in high school in Brazil is well below that of current science and technology and that teachers are dissatisfied with their everyday practice. To defend the thesis that it is necessary break with the current teacher's work structure if we desire an autonomous, critical and democratic scientific training we study the teaching work in the logic of contemporary capitalism and how physics and research in physics education have been constructed. We applied a questionnaire to mid-level physics teachers from public schools in São Paulo and conclude that the reality of their work prevents them from preparing their lessons better in order to make physics alive, as they want to. They stay with their expository classes, teaching classical physics in the traditional way, demonstrating the need for urgent changes.
\end{abstract}

Keywords: Teaching work. Physics teaching. High school. Teacher training. Public school.

\footnotetext{
${ }^{1}$ Instituto Federal de Educação, Ciência e Tecnologia de São Paulo (IFSP), São Paulo, SP, Brasil.

Orcid: <http://orcid.org/0000-0002-4550-2659>. E-mail: <renato.pugliese@ifsp.edu.br>.
} 


\section{Introdução}

O texto que segue versa sobre a organização do trabalho do professor de Física no Ensino Médio na cidade de São Paulo, e explicita parte dos resultados da pesquisa desenvolvida entre 2012 e 2016 dentro do Programa de Pós-Graduação em Educação da Faculdade de Educação (FE) da Universidade de São Paulo (USP), nível de doutorado (PUGLIESE, 2016).

Em trabalhos anteriores (PUGLIESE, 2011; PUGLIESE, ZANETIC, 2015) foi percebido que havia um espaço não ocupado entre a docência na educação básica, a pesquisa e o desenvolvimento tecnológico, ou seja, a partir da análise de resultados de investigação, percebeuse que o professor da educação básica parece não dialogar, não comunicar, com o pesquisador ou o desenvolvedor tecnológico.

Há, portanto, uma aparente contradição: se o pesquisador em Educação ou Ensino de Física desenvolve, entre outras coisas, metodologias, materiais, procedimentos, interpretações e modelos para a melhoria do processo educativo em nível básico, por que os professores não modificam suas práticas e permanecem com aulas conservadoras, tradicionais e/ou espetaculares?

Além disso, se a tecnologia industrial tem se mostrado tão integrada com a Física do século XX e está tão presente no cotidiano dos jovens estudantes e dos professores do ensino médio, por que a Física ensinada nas escolas parece tão isolada e distante do mundo real?

Esta presente pesquisa buscou, então, a compreensão de onde estão os nós que inviabilizam o diálogo entre escola e universidade, entre docência e pesquisa, segundo a hipótese de que a estrutura de trabalho dos professores de nível médio e dos pesquisadores em Ensino de Física não permite que haja diálogo entre eles (no sentido crítico, de idas e vindas, na práxis) e, portanto, parte significativa da Pesquisa em Ensino de Física (PEF) não tem alcance social, senão para obtenção de títulos e incrementos salariais, como uma "fuga para o alto", e parte significativa do ensino básico não tem inovação, ou seja, perpetua a reprodução alienada de conceitos.

É fácil encontrar, voltados à inovação no ensino da Física, trabalhos de pesquisa que sugerem atividades com modelos experimentais, laboratórios bem equipados ou com equipamentos de baixo custo, a utilização de novas tecnologias, tecnologias da informação e comunicação (TICs) e novas mídias, a utilização de conceitos/experimentos de Física moderna e relatividade na sala de aula de nível básico, a utilização da história e da filosofia da ciência, e algumas mais isoladas, como a sugestão da construção de mapas conceituais e diagramas pelos alunos, ou mesmo trabalhos fazendo a ponte entre arte e ciência (PUGLIESE, 2011; SALEM, 2012).

No entanto, faz-se necessário compreender as relações de trabalho que parecem não permitir que estas centenas de propostas se estabeleçam em sala de aula. O ensino de Física, em geral, continua tradicional. Vale notar também que muitos trabalhos da PEF são realizados em campo, em sala de aula, com estudantes e professores reais em escolas reais; mas vale notar também que a grande maioria desses projetos pilotos encerram-se ali mesmo, no instante em que são publicados e deixam de existir.

Há ainda um conflito, quanto da Pesquisa em Educação (PE), sobre a organização do trabalho docente. Encontramos diversos trabalhos em revistas especializadas, como na Educação e Pesquisa, revista da Faculdade de Educação da USP, e nos trabalhos da Rede Estrado (Rede Latino-americana de Estudos sobre Trabalho Docente), acerca da organização do trabalho do- 
cente nas sérias iniciais do ciclo básico - educação infantil e ensino fundamental ${ }^{2}$ (GASPARINI; BARRETO; ASSUNÇÃO, 2005; MASSABNI, 2011) e encontramos artigos sobre propostas e projetos para o ensino de Física no nível médio (geralmente organizados por licenciados em Física ou pesquisadores em Ensino de Física) em revistas como a Revista Brasileira de Ensino de Física ou o Caderno Brasileiro de Ensino de Física. Contudo, raramente identificamos investigações que busquem estabelecer fundamentos da organização do trabalho docente em nível médio, em especial de Física, e este pode ser um dos nós que engessam o diálogo entre pesquisa e Ensino de Física no Brasil.

Num levantamento acerca da produção acadêmica sobre trabalho docente na educação básica no Brasil entre 1987 e 2007, “[...] foram encontrados 467 trabalhos, sendo 388 dissertações e 79 teses" (DUARTE, 2010, p. 103), sendo que destes, apenas $11 \%$ dizem respeito ao Ensino Médio e, certamente, pouco ou quase nada sobre o trabalho dos professores de Física no Ensino Médio, visto que, de todos os 467 trabalhos, apenas $6 \%$ versam sobre condições de trabalho docente.

Sendo assim, o foco desta pesquisa esteve em compreender os limites das relações entre ensino de Física e pesquisa no Brasil, pensando na organização do trabalho do professor, com o objetivo de responder a seguinte questão: É possivel haver mudança significativa no ensino de física a partir de novos projetos e propostas curriculares dentro da estrutura organizacional de trabalho vigente?

Nas próximas seções serão discutidos fundamentos teóricos quanto ao que vem a ser, ou vinha sendo, o Trabalho Docente, o que é essa área científica chamada Física e o que tem sido produzido em Pesquisa em Ensino de Física. Ademais, será apresentado o trabalho de campo, sua metodologia e o contato com os professores do ensino básico, bem como os resultados da pesquisa e as considerações finais.

\section{O trabalho docente}

Nos últimos séculos, especialmente da primeira revolução industrial aos dias atuais, o trabalho humano, enquanto produção da existência material, tem se dividido entre os que detêm os meios de produção (ricos) e os que não os detêm (pobres) e, portanto, precisam oferecer sua mão de obra em troca de um salário. Salário este que, em grande parte do mundo não é suficiente sequer para a alimentação e a sobrevivência animal.

O sistema capitalista, ao longo do século XX, aprendeu a controlar o trabalho não apenas dentro das indústrias, mas também fora delas, formando o trabalhador para a reprodução do capital em seus momentos de lazer, em sua infância, em sua formação educacional, de modo que quase a totalidade dos ambientes frequentados pelos trabalhadores atua como formador e gerador de lucro por meio da exploração da mais-valia relativa (BRUNO, 1997, 2011; MÉSZÁROS, 2008), da qual podemos perceber como o espaço e o tempo dos trabalhadores fora das empresas vêm sendo explorados.

\footnotetext{
${ }^{2}$ Em geral realizados por pesquisadores graduados em Pedagogia, com direcionamento para a faixa etária de 6 a 13 anos.
} 
O trabalhador que anteriormente quase não possuía tempo livre devido às extensas jornadas de trabalho começa a se organizar no final do século XIX e a requisitar menores intervalos de tempo nas fábricas. O capital, percebendo que os trabalhadores estavam sucumbindo à extrema exploração com sua saúde e, por conseguinte, produzindo menos, compreende que a diminuição das jornadas pode contribuir para uma produtividade maior e, diretamente, lucros maiores, fato que seria consumado durante o século XX.

Desse modo, é fácil identificar que após a metade do século XX a exploração da maisvalia relativa se tornou tão ou mais necessária do que a mais-valia absoluta. O capitalismo se estendeu para esferas cada vez maiores da vida dos cidadãos, ocupando de modo quase integral seu tempo de vida.

Outra mudança importante está na hierarquia da pirâmide social mundial. O que representava o lugar das tomadas de decisões, o Estado, hoje sustenta o papel de operacionalizador e implementador das ações decididas pelos que estão no vértice da pirâmide social, a saber, as corporações transnacionais (BRUNO, 1997). Neste sentido, o sistema político que nasce desta estrutura é o neocorporativismo informal, pois no vértice das relações corporativistas estão as grandes empresas e não o Estado e pois, apesar de o Estado regulamentar dentro de sua legislação a atuação das grandes empresas, a estrutura de poder (transnacional) não está juridicamente estabelecida ${ }^{3}$.

Para tanto, os mecanismos de controle dessas empresas extrapolam a esfera do interior físico das instituições, como já dito anteriormente, e passam a atuar durante todo o tempo de vida social, além do profissional, dos trabalhadores. "A indústria do entretenimento abarca praticamente a totalidade do lazer dos trabalhadores, veiculando-se por aí não apenas valores culturais e éticos, mas formas disciplinares que moldam comportamentos e atitudes, a partir da lógica das grandes empresas" (BRUNO, 1997, p. 25). É comum encontrarmos hoje anúncios de vagas de trabalho solicitando "colaboradores", e não funcionários. Busca-se o empregado que está em consenso com as regras da empresa, com as condições de trabalho, com sua cultura.

E para que haja essa complacência entre trabalhador e empregador, o mesmo precisa ser qualificado/formado de tal maneira que acate, aceite e consensue com o modo de produção capitalista vigente. A formação da estrutura psíquica do trabalhador para que seja qualificado a ponto de "colaborar" com as empresas inicia-se desde seu nascimento, ou seja, nos produtos que se utiliza ainda bebê, nos presentes recebidos, na estrutura familiar, nos passeios em shoppings centers, no assistir da televisão, nas roupas que se veste, nos filmes a que assiste, no futebol a que se torce, nos veículos em que se locomove e, não obstante, nas escolas que frequenta.

\footnotetext{
${ }^{3}$ Veja o caso da atuação da FIFA no Brasil entre os anos de 2008 e 2014 durante o planejamento, a organização e a realização da Copa do Mundo de Futebol, em 2014. A imposição das vontades desta instituição, que possui sede em Zurique, Suíça, fez com que o Governo Federal criasse uma legislação específica para o período de realização do evento, a chamada Lei Geral da Copa. Aprovada pelo Congresso Nacional em março de 2012 e publicada pelo Diário Oficial da União em junho do mesmo ano, dois anos antes do evento, o documento fazia diversas suspensões e alterações em artigos e regulamentos nacionais em prol das regras da FIFA. "A Lei Geral da Copa suspende, por um período anterior e posterior ao evento, artigos das leis de Patentes e dos Estrangeiros; dos estatutos das Cidades, do Torcedor e dos Idosos; e leis municipais que garantem o direito de ir e vir" (ARRUDA, 2012).
} 
Educamo-nos enquanto cidadãos e seres humanos racionais em todos os meios que frequentamos do nascimento à morte. Conhecemos a língua, os costumes, o modo de se vestir, de tratar o próximo, o que comer e beber, do que reclamar, o que elogiar, entre tantas outras questões, a princípio, no âmbito familiar. Ao mesmo tempo, da infância à idade adulta, compartilhamos a nossa vida dentro dos muros da escola, reconhecendo outras maneiras de utilizar a linguagem, outros costumes, outros modos de se vestir, de comer e de beber, outras reclamações, outros elogios e, mais especificamente, outros modos de pensar o mundo a partir da apropriação da cultura humano histórica. A escola cumpre, desse modo, funções próprias do que chamamos de educação escolar.

No mundo atual, onde a escolarização está cada vez mais tornando-se obrigatória, nem sempre os objetivos finais desta formação estão direcionados aos conceitos de democracia ou autonomia do indivíduo, mas sim à alienação e à produção de mais-valia relativa (PARO, 2011). Da educação exclusiva da elite no início do século XX aos dias de hoje, a educação escolar obrigatória cumpre, nem tanto implicitamente, funções diretamente voltadas à formação da massa que será explorada posteriormente. No entanto, os conflitos naturalmente surgem e, desse modo, a violência (e a dominação) pode ser deixada de lado se cada indivíduo "entende" que há o diálogo. É o espetáculo (DEBORD, 1997) em sua essência, ou seja, a aparência do diálogo enquanto há alienação e autoritarismo. Faz-se necessário, portanto, para o capital, organizar o sistema de tal maneira que seja possível manter o controle sobre uma cada vez maior parcela da população, objetivando o controle de todos e a manutenção da ordem.

Neste contexto, o professor da educação básica, trabalhador assalariado, participa do sistema de produção geral ocupando papéis quase nunca esperados ou planejados por ele, seja pela falta de condições objetivas de trabalho, seja pela realista manutenção da ordem de separação das classes.

A crescente universalização ${ }^{4}$ da educação básica iniciada há algumas décadas e, atualmente, contemplando a obrigatoriedade da presença cotidiana das crianças e jovens no interior das escolas, criou uma esfera de trabalho para o professor e de estudo para os estudantes que, por vezes, inviabiliza qualquer possibilidade de atuação enquanto sujeitos, seja da manutenção, seja da transformação. Em algumas análises, esta inviabilidade de trabalho é proposital, e cumpre seu papel, pois possui sentido de desqualificar o trabalho e a autoridade intelectual e criar disciplina e controle de comportamento pelo autoritarismo hierárquico banal, como se este fosse um processo natural (a obediência pela obediência) do capitalismo. Em outras análises, esta inviabilidade também é considerada proposital, mas não está cumprindo seu papel, pois tem gerado uma crise aguda em que jovens e professores não compreendem o sentido de seu fazer, perdendo sua possível autonomia, sua participação ativa e, assim, estagnando a economia e a produção capitalista.

Geralmente "[...] se toma a docência por analogia a qualquer outro trabalho na produção econômica da sociedade” (PARO, 2011, p. 163). Além disso, para o trabalhador comum o único

\footnotetext{
${ }^{4}$ Vale notar que não entramos no mérito da diferença entre universalização, massificação, relação matrículas x frequência.
} 
motivo que o leva a realizar o seu oficio é o salário. Ele até pode gostar do que faz, mas só o faz pelo salário que irá receber. No caso do professor, seu "produto" a ser trabalhado, produzido, é "[...] um ser humano histórico, cuja propriedade característica é sua subjetividade" (PARO, 2011, p. 164). Dessa forma, “[...] o papel principal do professor não é a transformação passiva do objeto de trabalho, mas sim o de propiciar condições para que o próprio objeto de trabalho se transforme ao produzir a própria educação, que consiste na formação de sua personalidade, pela apropriação da cultura” (PARO, 2011, p. 165).

Sem o diálogo (relação política entre ambos - professor e estudante) o professor não realiza o seu trabalho (ainda que receba seu salário), enquanto que o trabalhador comum o faz (pelo salário), ou seja, o professor não provoca apropriação de um leque maior de cultura, e sim a manutenção do mesmo leque já estabelecido por outros meios.

No Estado de São Paulo, os professores da rede pública podem lecionar até 65 aulas por semana, além de aulas fora da rede pública (SÃO PAULO, 2013, 2014). Estes são apenas exemplos do caminho em contramão que vem sendo percorrido pelos gestores da educação brasileira, visto que entendendo a educação escolar como parte do processo de produção capitalista e, geradora de mais-valia relativa em essência, o aumento da jornada de trabalho só diz respeito a uma idealização ingênua/ignorante de que o aumento da mais-valia absoluta no processo escolar poderia gerar maior produtividade para as empresas capitalistas que estão envolvidas diretamente com esse processo (editoras, distribuidoras de material escolar, de alimentos, etc.) e das que estão aguardando a formação qualificada (por competências, habilidades, disciplina e comportamento) dos estudantes em médio prazo.

Desse modo, podemos concluir que a natureza do trabalho docente faz com que ele não possa ser diretamente comparado com o trabalho de um operário em linha de produção, ou um funcionário do comércio ou mesmo de administradores de empresas, pois não gera maisvalia diretamente, a curto prazo. Contudo, e com maior significado, seu trabalho não pode ser excluído do processo de produção do capital, pois está em seu cerne, em sua prática diária, visto que é gerido pelo capital, o espetáculo da decadência e da desvalorização dos profissionais da educação, a destruição dos valores da intelectualidade e da autonomia, tornando assim por ser, o professor, um dos importantes produtores de massa populacional a ser explorada adiante pela mais-valia absoluta enquanto produz diariamente pacotes de mais-valia relativa.

\section{A Física e a PEF}

A ciência é uma atividade humana que vem sendo construída ao longo dos últimos milênios e que possui uma série de características bastante específicas, comparativamente às outras atividades humanas como a arte, a prática religiosa, a meditação e o esporte, tal qual a observação sistemática da natureza, de seus fenômenos, seus sujeitos e objetos, a análise e o estudo dessas observações, a categorização de aspectos comuns, diferentes e opostos envolvendo temas materiais e não materiais, a construção e a reconstrução da história; a previsão de fenômenos, processos e comportamentos naturais (humanos ou não) e culturais, entre outros.

Da origem do pensamento reflexivo aos dias de hoje a ciência sofreu uma expansão enorme, especialmente no que diz respeito à parcela da população mundial envolvida diretamente com processos e resultados científicos, visto que 
[...] qualquer sociedade atual, não importando quais sejam seus cultos religiosos ou sua organização social e política, faz uso da eletricidade, de transportes automotivos, de vacinação, de radiocomunicação e de inúmeras outras técnicas, que são manifestações e instrumentos práticos da cultura científica e tecnológica (MENEZES, 2005, p. 5).

Ainda que muitos pensadores investigaram a natureza e suas relações causais, anteriores ao período de domínio da filosofia grega entre os séculos VI e II a.C, como no taoismo, no budismo e no confucionismo, é com os gregos que aprendemos a sistematizar o estudo da natureza de um modo mais próximo do que conhecemos como Física atualmente. Essa forma de olhar para o mundo, essa filosofia sistemática, tal qual a conhecemos, aparentemente surgiu com os gregos há alguns séculos antes da era cristã (SCHENBERG, 2001; ZANETIC, 2004) e permitiu que o homem abrisse, por vezes em pequenos grupos, espaço para compreender diversos fenômenos naturais, situações, processos e comportamentos que anteriormente não lhe era possível.

Dos gregos e romanos, passando pela enorme contribuição árabe durante a idade média e culminando nos renascentistas europeus, a Física tomou forma e passou a crescer de forma exponencial nos últimos três séculos enquanto desenvolvimento científico e atuação social (FEYNMAN, 2001; KUHN, 1975; RASHED, 1996; ZANETIC, 1989). A investigação da história e do desenvolvimento científico, doravante chamada epistemologia, mostra que a Física não evolui de forma linear, nem tampouco cumulativa, como apresentado na grande maioria dos textos didáticos e desenvolvido nas aulas ditas tradicionais. A evolução da Física é repleta de revoluções, crises, mudanças de paradigmas e abstrações fundamentais. Esse conjunto de ações é entendido de formas muito diferentes; por um lado porque a comunidade dos físicos, ou sua tribo (LATOUR, 2000), pertence a um contexto espaço-temporal (político-sócio-cultural) muito bem definido e, por outro, porque cada físico deve ter uma visão de mundo muito peculiar.

A transição de um paradigma antigo para um novo é conflitante, pois não se trata de um processo cumulativo, e sim de alterações estéticas fundamentais. Enquanto a ciência normal se faz pela articulação e aprimoramento de conceitos e técnicas, especialmente de aparelhos e instrumentos, o período de revolução científica gera problemas estruturais na forma como se vê o mundo, ou seja, torna-se necessário reconstruir generalizadamente as teorias vigentes, métodos e processos.

Sendo assim, a ciência vem sendo construída ao longo dos séculos não de forma isolada dentro dos laboratórios e centros acadêmicos, mas como parte de toda a construção de realidade material da humanidade, partilhando visões de mundo, contextos políticos, articulações, combinações e colonizações que permitiram a aceitação de determinados conceitos e teorias (paradigma) num dado instante e de outras teorias em outros momentos.

Fica cada vez mais claro que a Física só pode existir enquanto cultura humana, definição que não parece estar presente no cotidiano escolar dos jovens e adultos brasileiros, pois

[...] quando se comenta sobre a cultura, de um modo geral, raramente a Física comparece de imediato na argumentação, ou outra representante das ciências naturais dá o ar de sua graça. Cultura, quando pensada "academicamente" ou com finalidades educacionais, é quase sempre evocação 
de alguma obra literária, alguma grande sinfonia ou uma pintura famosa; cultura erudita, enfim. Tal cultura traz à mente um quadro de Picasso, uma sinfonia de Beethoven, um livro de Dostoyevsky, enquanto que a cultura popular faz pensar em capoeira, num samba de Noel ou num tango de Gardel. Dificilmente, porém, cultura se liga ao teorema de Godel ou às equações de Maxwell (ZANETIC, 1989, p. 145-146).

A noção de que a ciência não é cumulativa e de que é construída como parte do sistema político, dos padrões religiosos, das manifestações artísticas e do pensamento filosófico e metafísico necessita, como defesa nossa, ser cada vez mais trabalhada nas escolas de base. Apesar de o Brasil atualmente figurar no cenário mundial como uma das grandes economias do mundo capitalista, o incentivo à pesquisa científica e ao desenvolvimento tecnológico ainda é muito baixo.

O professor de Física que atua na educação básica, quase que exclusivamente no ensino médio no Brasil, tem a função, portanto, de realizar o seu trabalho (enquanto assalariado) ensinando aos jovens o que é esse fazer social, essa tarefa sem fim de investigar a natureza quanto aos seus aspectos físicos, na busca por relações particulares e leis gerais que nos permitem pensar melhor sobre o que somos, de onde viemos e para onde vamos, além de auxiliar no desenvolvimento de novas tecnologias e na melhoria do conforto humano.

Atualmente no Brasil o ensino de Física é obrigatório durante os três anos do ensino médio em disciplina específica, no eixo Ciências da Natureza (BRASIL, 1996), e não é de hoje que o ensino de Física nas escolas básicas vem sendo questionado quanto ao seu papel, sua forma e sua consequência. A precariedade do ensino oferecido, quando idealizamos a formação do cidadão emancipado, autônomo e livre para escolher sua profissão e seus afazeres futuros, é tamanha que a quantidade de pesquisas desenvolvidas nas últimas décadas que buscam compreender o ensino de Física e oferecer recursos, métodos, materiais e questionamentos acerca de sua melhoria só tem crescido, como veremos adiante.

Para Salem (2012), na gênese e no desenvolvimento evolutivo da Pesquisa em Ensino de Física (PEF) no Brasil na década de 1960 há uma marca notável: uma demanda pelo aprimoramento do aprendizado do conhecimento científico, com o objetivo de que ele seja mais eficiente. A reformulação do ensino médio, no final da década de 1990 e início dos anos 2000, influenciou e explicitou a necessidade da ampliação da PEF e gerou, por outros motivos também como a universalização do ensino básico e o crescimento da economia, um aumento significativo dessa área de trabalho.

A PEF tem como limites e/ou problemas principais o diálogo com a sala de aula, mas tem como tendência uma maior penetração social, visto que há uma “[...] ausência ou pouca penetração, intercâmbio ou diálogo entre a pesquisa e a sala de aula, entre a produção do conhecimento sobre o ensino e o próprio ensino, entre a teoria e a prática, entre o pesquisador e o professor" (SALEM, 2012, p. 63).

Mas essa é uma contradição, a princípio, curiosa: se a origem e o desenvolvimento da PEF tem como característica peculiar a motivação pela melhoria do ensino e da aprendizagem em sala de aula de nível básico, e tem crescido sistematicamente nas últimas décadas, por qual razão um de seus maiores problemas é o diálogo com a sala de aula e os professores de nível básico?

Para Salem (2012, p. 156), “[...] em alguns casos, incluem-se, nesse conjunto, diagnósticos das condições de trabalho de professores, perfil socioeconômico ou concepção de pro- 
fessores sobre assuntos diversos", ou seja, das mais de 1300 dissertações e teses avaliadas pela pesquisadora, "em alguns casos" há "diagnósticos" das condições de trabalho de professores, o que nos indica a irrelevância com que o tema Trabalho Docente tem sido tratado pela PEF.

A PEF tem crescido de maneira substancial, entretanto, as condições de trabalho do professor de Física parecem ter sido deixadas de lado. Pesquisa há, e resultados também. Cada vez mais profundos, contextualizados e abrangentes. Cursos de licenciatura em Física também têm sido abertos em várias regiões do país. Documentação e legislação têm sido criadas para ampliar e contextualizar o ensino em geral. Mas e os professores de nível básico? Algumas perguntas devem ser feitas para que possamos entender onde se dá a ruptura entre a pesquisa e a prática docente. Os professores têm acesso aos resultados das pesquisas? Utilizam os resultados em seus planejamentos, construções e cotidiano? Suas condições de trabalho permitem esse diálogo?

\section{Ouvindo os professores}

Para estudar as relações entre o professor de Física, as áreas de pesquisa e de conhecimento humano detalhadas nas seções anteriores (a física, a educação e o ensino de física) e a produção de sua vida material (seu trabalho) no sistema econômico brasileiro, foi aplicado um questionário com os mesmos, contendo questões objetivas fechadas, semiabertas e abertas.

Como o objeto da pesquisa esteve na análise qualitativa de uma amostra bastante restrita de dados, e ainda que os dados tenham sido plotados e tabelados, a quantidade de professores participantes não é representativa de toda a classe profissional, bem como o contexto e o período de coleta de dados, bastante transversal. Assim o estudo não é estatístico e nem tampouco generalizável. Não é do tipo Survey, sendo muito mais apropriado classificá-lo como um Estudo de Caso (CESAR, 2005).

O recorte escolhido para o trabalho de campo foi o seguinte:

i. professores de Física: que estivessem lecionando Física regularmente em turmas de ensino médio;

ii. ensino médio: apesar de parte do conteúdo sugerido nos PCN para trabalho no ensino fundamental estar vinculado à Física, é no ensino médio que essa área do conhecimento humano ganha foco e possui disciplina específica;

iii. escolas públicas: professores que lecionam no ensino médio da rede pública municipal, estadual e federal;

iv. cidade de São Paulo: por questões de logística, esta cidade foi o palco. No entanto, houve contato com escolas ora em bairros mais periféricos, ora mais centrais.

Para a aplicação dos questionários, visitamos escolas públicas na cidade de São Paulo e conversamos pessoalmente com trinta e um (31) professores de física com aulas regulares no ensino médio entre 2014 e 2015. Os questionários foram entregues aos professores para análise e viabilidade da participação, sendo que poderiam ser respondidos no ato, entregues em visita posterior ou mesmo via formulário eletrônico online. Inicialmente dez (10) professores enviaram as respostas (apenas um pessoalmente e os outros nove por via eletrônica). Num segundo contato com os vinte e um (21) professores que não haviam retornado, seis (6) deles enviaram suas respostas por via eletrônica. Ainda num terceiro contato com os quinze (15) restantes, alguns responderam que não poderiam participar da pesquisa, ainda que tenham sido avisados do sigilo dos dados, e outros não retornaram, portanto, foram descartados do trabalho. Trabalhamos então com dados de dezesseis (16) professores. 
As questões foram elaboradas seguindo o objetivo de investigar como os professores de Física de nível médio lidam com seu trabalho (o trabalho docente), com a disciplina que lecionam (a física enquanto ciência e cultura) e com a produção e os resultados das pesquisas que vêm sendo feitas nas últimas décadas (sobre ensino de física, de ciências ou sobre educação em geral). Dessa forma o questionário foi dividido em três blocos, a saber:

Bloco 1 - organização do trabalho: este bloco, com 12 questões, teve como objetivo levantar dados sobre quanto e como se trabalha dentro e fora da sala de aula, ou seja, sobre qual o valor de uso do trabalho do professor; levantar também alguns dados sobre quanto se recebe para a realização deste trabalho, ou seja, seu valor de troca e, por fim, questionar sobre qual o objetivo do trabalho do professor de nível médio, ou seja, para quê se formam os alunos, se para a produção de mais-valia relativa ou outras finalidades.

Bloco 2 - Física enquanto ciência e cultura: este bloco, com 5 questões, teve como objetivo compreender como o professor responsável pela disciplina de Física interpreta a natureza da ciência, seu fazer e seu desenvolvimento histórico, e como ele avalia a compreensão de seus alunos acerca do fazer científico e da estrutura da ciência. Em outros termos, as questões circundam assuntos como o que é ensinar Física, para quê ensinar Física e com o quê se ensina Física.

Bloco 3 - a pesquisa em ensino de Física: este bloco, com 5 questões, teve como objetivo compreender a intensidade do diálogo entre o professor de Física e a pesquisa em ensino de Física, ou seja, se ele tem formação em alguma área que esteja vinculada necessariamente com a pesquisa em ensino, como as licenciaturas em Física ou os mestrados em ensino/educação, e qual sua intimidade com resultados de PEF.

Os dados coletados, plotados em gráficos e tabelas, estão disponíveis em Pugliese (2016). Apesar de ser uma pesquisa sem fim estatístico, os dados foram reunidos em percentuais para compactar as informações.

\section{Realidade, vontade e necessidade}

O tempo e o espaço de trabalho do professor de Física está concentrado nas seguintes situações, que descrevem sua realidade:

1. $57 \%$ trabalham em mais de uma unidade escolar;

2. $38 \%$ compartilham aulas entre sistemas públicos e privados;

3. $\quad 50 \%$ lecionam Física e mais alguma outra disciplina;

4. $\quad 44 \%$ ministram mais de 30 aulas por semana;

5. $100 \%$ lecionam de 1 a 3 aulas de Física por semana por turma;

6. $\quad 50 \%$ têm, em média, mais de 35 alunos por classe;

7. $82 \%$ recebem no máximo 5 horas-aula semanais para trabalhos extraclasse;

8. $88 \%$ recebem no máximo 5 horas-aula semanais para trabalhos extraclasse fora da carga horária;

9. $44 \%$ recebem até $\mathrm{R} \$ 2900,00$ mensais numa jornada de 40 horas semanais e $50 \%$ recebem entre $\mathrm{R} \$ 2900,00$ e $\mathrm{R} \$ 7250,00$;

10. $94 \%$ não participam ativamente de nenhum sindicato;

11. As aulas são quase que exclusivamente expositivas de conteúdo;

12. As atividades realizadas com os alunos são pautadas em resoluções de exercícios conceituais e matemáticos, com experimentação demonstrativa;

13. $75 \%$ escolhem o material didático utilizado; 
14. Nenhum professor afirma que seus alunos, em geral, aprendem Física;

15. $94 \%$ têm cursos de pós-graduação;

16. Os 10 temas mais ensinados são da Física Clássica, desenvolvida até o séc. XIX;

17. Os 10 temas menos ensinados são da Física Moderna, do século XX;

18. $50 \%$ dos professores conhecem bem alguns temas da PEF.

Os professores passam quase a totalidade de seu tempo de trabalho remunerado dentro de salas de aula, lecionando para várias turmas, estas que são no geral bastante populosas. O tempo do professor fora da sala de aula está concentrado em locomoções entre unidades escolares e outros afazeres.

O trabalho é feito de modo individual e basicamente mecânico. Não há tempo disponível para a articulação entre professores, para o trabalho reflexivo ou para a pesquisa e a investigação dos problemas cotidianos e da busca por mudanças educacionais ou inovações, nem sequer de implementações de reformas impostas por forças externas. É fácil perceber que grandes sugestões de inovações não interferem significativamente na realidade da sala de aula, mesmo após muitos anos.

A desvalorização do trabalho docente fica explícita quando notamos que praticamente todos os professores, apesar de possuírem 10 ou mais anos de experiência e cursos de pósgraduação, ainda recebem salários inferiores aos mínimos de outras categorias onde o diploma de ensino superior também é requisitado.

Os temas ensinados nessas aulas tradicionais são os também tradicionais temas presentes na chamada Física Clássica, desenvolvida até fins do século XIX. Em contrapartida, o cotidiano dos habitantes (professores, estudantes e comunidade) de uma cidade como São Paulo é recheado de tecnologia desenvolvida com a chamada Física Moderna, construída ao longo do século XX.

Há uma tentativa vã de se ensinar Física como se esta fosse construída de forma linear: primeiramente tenta-se ensinar a Física Clássica para, se possível, alcançar o estudo da Física Moderna (que não se alcança). Tenta-se ensinar os conceitos para, se possível, fazer experimentações (que não são feitas). É o contrário da Física, enquanto ciência e cultura. Essa é uma atitude impensada, não reflexiva, que remete ao senso comum e à manutenção da ordem de classe social. Não se faz investigação experimental e, portanto, não há erros, apenas as certezas dos livros didáticos. Não há revolução científica, não há incertezas, há apenas condicionamento ético. É a produção explícita da mais valia relativa. Esse trabalho reproduz as conhecidas e tão criticadas aulas tradicionais: giz e lousa, apesar de a quase totalidade dos professores possuírem diploma de cursos de pós-graduação e apresentarem conhecimento razoável de temas da PEF.

Em contrapartida, podemos identificar os seguintes padrões de desejos nas respostas dos professores, sua vontade:

1. $88 \%$ acreditam que dariam melhores aulas se tivessem mais tempo remunerado para estudar, prepará-las e avaliar o andamento dos cursos;

2. $56 \%$ indicam que um professor deveria receber entre $\mathrm{R} \$ 2900,00$ e $\mathrm{R} \$ 7250,00$ para a jornada de 40 horas semanais no início de carreira; 38\% indicam que deveria ser entre $\mathrm{R} \$ 7250,00$ e $\mathrm{R} \$ 14500,00$;

3. $94 \%$ não participam ativamente de organizações sindicais docentes, mas muitos destes afirmam que o motivo da não participação é a desarticulação ou desorganização dos grupos sindicais;

4. $94 \%$ consideram necessário a experimentação em aulas de Física; 
5. $63 \%$ consideram necessário a realização de visitas externas e de exercícios práticos-experimentais e a leitura de textos didáticos;

6. $\quad 56 \%$ consideram necessário a leitura de textos histórico-científicos;

7. $100 \%$ afirmam que apenas a formação inicial, para a prática docente, não basta;

8. $44 \%$ indicam que o aumento de salário é o principal item para melhoria do ensino (política pública);

9. $50 \%$ indicam que a formação dos professores e a quantidade de aulas/semana ou alunos/classe são os itens mais significativos para melhoria do ensino (política pública);

10. Apenas $6 \%$ afirmaram que para melhoria do ensino a comunidade precisa participar mais e nenhum professor apontou para a formação familiar dos alunos (questões locais).

Os professores têm a certeza de que o tempo de trabalho deles está mal distribuído e que, por conta disso, não conseguem realizar os cursos que gostariam com seus alunos. Desejam ter mais tempo de trabalho extraclasse, especialmente no que diz respeito ao trabalho individual, para a melhor preparação das aulas e cursos, para continuar estudando e inovando em sala de aula, buscando práticas experimentais e inovações tecnológicas e trazendo textos didáticos e histórico-científicos para a leitura dos estudantes. Eles sabem disso.

Sabem também que apenas a formação inicial não é suficiente, de que o verdadeiro trabalho docente está pautado no estudo permanente frente às transformações científicas e sociais, e apontam vontade de estudar sempre, como parte do trabalho.

Para além do desejo de mais tempo de trabalho extraclasse individual, eles demonstram querer mais tempo de trabalho coletivo, para reflexão sobre as organizações de classe, para a reestruturação dos sindicatos e das equipes gestoras, visto que indicam desejar aumento de salário, melhor formação inicial e continuada, redução da carga horária em sala de aula e redução do número de alunos por turma.

A maioria dos professores idealiza um salário, apesar de maior do que o atual, abaixo das outras profissões que têm como requisito formações equivalentes, certamente devido à extrema desvalorização dos vencimentos da categoria nas últimas décadas. Os professores de Física também desejam melhoras e sabem da importância dessas mudanças, além de perceberem que grande parte do problema é externo (políticas públicas). As condições impostas, contudo, inviabilizam grande parte das ações estruturantes: há inovações, geralmente individuais ou de pequenos grupos, que não levam a transformações globais.

Desse modo, identificamos alguns pontos que descrevem a necessidade de mudanças no trabalho do professor de física de nível médio. A carga horária de trabalho em sala de aula está além do possível. Apesar de passados mais de nove anos da publicação nacional da Lei 11738/08 (BRASIL, 2008, p. 1), a qual afirma que “"...] na composição da jornada de trabalho, observar-se-á o limite máximo de $2 / 3$ (dois terços) da carga horária para o desempenho das atividades de interação com os educandos", os professores ainda não usufruem do $1 / 3$ de tempo de trabalho que deve se dar a atividades extraclasse, dada a realidade descrita acima.

Em alguns casos, como o dos profissionais das ETEC, geridas pelo Centro Paula Souza, há no salário o valor de 30\% (menos do que os 33\% previstos em lei) da atividade em sala de aula para ser usufruído como hora-atividade, na descrição da lei estadual que regulamenta esse intervalo de trabalho, 
[...] entende-se por hora-atividade o tempo despendido em atividades extraclasse para atendimento a alunos, reuniões previstas em calendário escolar, planejamento, avaliações de aproveitamento e curriculares, preparo de aulas e de material didático e outras próprias da docência. (SÃO PAULO, 2014, p. 1).

Sendo que “[...] o tempo destinado às horas-atividade corresponderá [...] a 30\% (trinta por cento) do número de horas-aula efetivamente ministradas” (SÃO PAULO, 2014, p. 1). Este caso é exceção, ainda que esteja abaixo do previsto em lei, visto que a maioria dos professores afirmou não ter tempo remunerado para além de 5 horas-aulas semanais, em jornadas que ultrapassam as 30 horas-aulas semanais em sala de aula. Na prática, são tantas horas em sala de aula, muitas vezes em duas ou três escolas, e tão desvalorizado o salário, que o professor desconhece ou não usufrui desse valor recebido como deveria.

Dessa realidade não satisfatória, e da vontade de estudar mais, interagir mais com colegas de profissão, equipe gestora e grupos sindicais, podemos afirmar a necessidade do cumprimento de tempo de trabalho individual e coletivo dentro do ambiente escolar, situação que não ocorre, em geral: apesar de constar nas folhas de pagamento e na legislação atual, o pouco tempo remunerado recebido pelos professores é subutilizado, visto que trabalham com muitas classes e em muitas escolas. Podemos até afirmar que utilizam mais tempo para correção de avaliações e preparação de aulas do que recebem, ainda que esse ponto não tenha sido explorado no questionário.

Ainda com relação ao salário, é importante notar a necessidade de valorização do trabalho docente, tanto no âmbito do valor de troca, já mencionado, quanto ao valor de uso. Os professores sentem que seus alunos não apreendem os conceitos físicos e qual o papel dessa área da ciência, além de não identificarem de forma unânime a função do ensino médio na vida da juventude cidadã. Ao declararem que o salário ideal para um professor se encontra no limiar do salário mínimo de outras profissões, percebemos o sentimento de classe inferior. A ética (no sentido das relações sociais) e a estética (no sentido da forma) precisam mudar.

O ensino de física, sua forma e seu conteúdo curricular, precisa de mudanças bruscas: os professores desejam inserir mais tópicos de física moderna, desejam fazer mais experimentações, desejam visitar centros de ciências e museus, além de desejarem que seus alunos leiam mais (textos didáticos e históricos). Em sua prática, afirmam escolher qual material didático será adotado, mas mostram que seus alunos não leem. Afirmam que estudam em cursos de pós-graduação e conhecem os temas da PEF, mas demonstram que ensinam os tradicionais tópicos da Física Clássica em aulas quase que exclusivamente expositivas. É preciso que trabalhem mais coletivamente e estudem mais individualmente, o que só será possível com mais tempo disponível para tal na referida unidade escolar.

Da pergunta feita no início deste trabalho, sobre se é possível haver mudança significativa no ensino de física a partir de novos projetos e propostas curriculares dentro da estrutura organizacional de trabalho vigente?, afirmo que não. A PEF, os documentos oficiais (PCN, $\mathrm{PCN}+$ ) e a legislação vigente pressupõem transformações na estrutura de trabalho docente, mas na prática essas transformações ou não ocorreram ou estão ocorrendo de forma tão lenta e pontual que não alcançará às transformações sociais e tecnológicas concomitantes.

Há a necessidade de que os professores atuem em apenas uma unidade escolar. Nenhuma das mudanças suscitadas acima será realizada enquanto os docentes lecionarem em unidades 
distintas, com calendários distintos, materiais didáticos distintos, alunos com perfil distintos, planos de carreira distintos, etc. Dito isto, afirmo ser necessário:

1. a valorização ética e estética do trabalho do professor;

2. a implementação de políticas públicas para o aumento de salário e plano de carreira eficiente;

3. fazer valer o cumprimento de, ao menos, $1 / 3$ do trabalho em atividades extraclasse, preferencialmente no local de docência (unidade escolar), individual e coletivamente;

4. definir de modo claro a função do ensino médio e da educação básica;

5. inserir a Física Moderna no cotidiano escolar;

6. investir em laboratórios didáticos e experimentações;

7. investir na atuação do professor como pesquisador; e

8. dar condições para que o professor trabalhe em apenas uma unidade escolar.

Ou seja, "[...] é por isso que é necessário romper com a lógica do capital se quisermos contemplar a criação de uma alternativa educacional significativamente diferente" (MÉSZÁROS, 2008 , p. 27, grifo do autor) e "[...] é preciso pensar o profissionalismo docente como um profissionalismo especial: da formação pessoal, do trabalho colaborativo/cooperativo e da capacidade de mudança social para a construção da democracia” (MOREIRA, 2013).

\section{Referências}

ARRUDA, F. O Brasil sob intervenção da FIFA. A Nova Democracia, Rio de Janeiro, v. 10, n. 88, abr. 2012. Disponível em: < http://www.anovademocracia.com.br/no-88/3948-obrasil-sob-intervencao-da-fifa>. Acesso em: 25 jan. 2015.

BRASIL. Lei no 9.394, de 20 de dezembro de 1996. Estabelece as diretrizes e bases da educação nacional. Diário Oficial da União, Brasília, 23 dez. 1996.

Lei no 11.738 , de 16 de julho de 2008. Regulamenta a alínea "e" do inciso III do caput do art. 60 do ato das disposições constitucionais transitórias, para instituir o piso salarial profissional nacional para os profissionais do magistério público da educação básica. Diário Oficial da União, Brasília, 17 jul. 2008.

BRUNO, L. Educação e desenvolvimento econômico no Brasil. Revista Brasileira de Educação, Rio de Janeiro, v. 16, n. 48, p. 545-562, 2011. Disponível em: < http:/ /dx.doi. org/10.1590/S1413-24782011000300002>. Acesso em: 26 out. 2017.

Poder e administração no capitalismo contemporâneo. In: OLIVEIRA, D. A. (Org.). Gestão democrática da educação: desafios contemporâneos. Petrópolis: Vozes, 1997. p. $15-45$.

CESAR, A. M. R. V. C. Método do estudo do caso (case studies) ou método do caso (teaching cases)?: uma análise dos dois métodos no ensino e pesquisa em administração. São Paulo: Universidade Presbiteriana Mackenzie, 2005. Disponível em: <http://www. mackenzie.br/fileadmin/Graduacao/CCSA/remac/jul_dez_05/06.pdf>. Acesso em: 23 nov. 2015.

DEBORD, G. A sociedade do espetáculo. Rio de Janeiro: Contraponto, 1997. 
O trabalho do professor de Física no ensino médio: ...

DUARTE, A. A produção acadêmica sobre trabalho docente na educação básica no Brasil: 1987-2007. Educar em Revista, Curitiba, n. esp. 1, p. 101-117, 2010. Disponível em: <https://doi.org/10.1590/S0104-40602010000400005>. Acesso em: 26 out. 2017.

FEYNMAN, R. P. Física em seis lições. Rio de Janeiro: Ediouro, 2001.

GASPARINI, S. M.; BARRETO, S. M.; ASSUNÇÃO, A. A. O professor, as condições de trabalho e os efeitos sobre sua saúde. Educação e Pesquisa, São Paulo, v. 31, n. 2, p. 189-199, 2005.

KUHN, T. S. A estrutura das revoluções científicas. São Paulo: Perspectiva, 1975.

LATOUR, B. Ciência em ação: como seguir cientistas e engenheiros sociedade afora. São Paulo: Ed. Unesp, 2000.

MASSABNI, V. G. Os conflitos de licenciandos e o desenvolvimento profissional docente. Educação e Pesquisa, São Paulo, v. 37, n. 4, p. 793-808, 2011.

MENEZES, L. C. A matéria, uma aventura do espírito: fundamentos e fronteiras do conhecimento físico. São Paulo: Livraria da Física, 2005.

MÉSZÁROS, I. A educação para além do capital. São Paulo: Boitempo, 2008.

MOREIRA, A. F. A docência e o currículo. In: ENCONTRO BRASILEIRO DA REDE DE ESTUDOS DO TRABALHO DOCENTE (REDE ESTRADO), 7., 2013, Vitória. Conferência de abertura.

PARO, V. H. Crítica da estrutura da escola. São Paulo: Cortez, 2011.

PUGLIESE, R. M. Consumindo a física na escola básica: a sociedade do espetáculo e as novas propostas curriculares. 2011. Dissertação (Mestrado em Ensino de Ciências) Universidade de São Paulo, São Paulo, 2011.

O trabalho do professor de física no ensino médio: realidade, vontade e necessidade. 2016. 163 f. Tese (Doutorado em Educação) - Faculdade de Educação, Universidade de São Paulo, São Paulo, 2016.

PUGLIESE, R. M.; ZANETIC, J. O ensino de física na sociedade do espetáculo: uma análise da implementação e do conteúdo em propostas curriculares. Caderno Brasileiro de Ensino de Física, Florianópolis, v. 32, n. 1, p. 32-52, 2015.

RASHED, R. Modernidade clássica e ciência árabe. Disponível em: < http:/ /hottopos.com/ collat6/roshdi2.htm>. Acesso em: 12 nov. 2015. Traduzido de RASHED, R. Modernité classique et science arabe. In: C. GOLDSTEIN, C.; RITTER, J. (Org.). Mathématiques en Europe. Paris: Ed. MSH, 1996. p. 68-81.

SALEM, S. Perfil, evolução e perspectivas da pesquisa em ensino de física no Brasil. 2012. 385 f. Tese (Doutorado em Ensino de Ciências) - Universidade de São Paulo, São Paulo, 2012. 
SÃO PAULO (Estado). Lei complementar no 1.240, de 22 de abril de 2014. Altera a lei complementar no 1.044, de 13 de maio de 2008, que institui o plano de carreiras, de empregos públicos e sistema retribuitório dos servidores do Centro Estadual de Educação Tecnológica Paula Souza - CEETEPS e dá outras providências. Diário Oficial [do] Estado de São Paulo, São Paulo, v. 124, n. 75, p. 1, 23 abr. 2014. Seção 1.

Lei complementar no 1207, de 05 de junho de 2013. Dispõe sobre os concursos públicos regionalizados para os integrantes do quadro do magistério da Secretaria da Educação, e dá providências correlatas. Diário Oficial [do] Estado de São Paulo, São Paulo, v. 123, n. 126, p. 1, 6 jul. 2013. Seção 1.

SCHENBERG, M. Pensando a física. São Paulo: Landy Editora, 2001.

ZANETIC, J. Física também é cultura. 1989. Tese (Doutorado em Educação) - Faculdade de Educação, Universidade de São Paulo, São Paulo, 1989.

FMT 405: evolução dos conceitos da física, parte 1: alguns tópicos de "filosofia" da ciência. São Paulo: Instituto de Física: Universidade de São Paulo, 2004. (Notas de aula). (Texto não publicado).

Artigo recebido em 30/07/2016. Aceito em 12/03/2017.

Endereço para contato: Instituto Federal de Educação, Ciência e

Tecnologia de São Paulo, Avenida Mutinga, 951, Pirituba, CEP

05110-000, São Paulo, SP, Brasil. 